Yuki Shimodate MD, Hironori Ishihara MD, Akitomo Matsuki MD

\title{
The initial distribution volume of glucose and cardiac output after haemorrhage in dogs
}

The purpose of the study was to evaluate the role of insulin in glucose kinetics after glucose administration using an insulinogenic index to indicate the magnitude of insulin response. The initial distribution volume of glucose (IDV-G) was calculated with a one-compartment model from repeated measurements of plasma glucose concentration three to seven minutes after administration of $100 \mathrm{mg} \cdot \mathrm{kg}^{-1}$ glucose. The $I D V$ $G$ was compared with the insulin response and the thermodilution assessments of cardiac output, measured simultaneously both before and afier induced haemorrhage $\left(30 \mathrm{ml} \cdot \mathrm{kg}^{-1}\right.$ over $30 \mathrm{~min}$ ) in 12 adult mongrel dogs. The plasma insulin concentration was measured during the procedure and insulinogenic indices were calculated. There was no correlation between the IDV-G and insulinogenic indices, but there was a correlation between the IDV-G and thermodilution cardiac output before and after induced haemorrhage $(r=0.85, n=24$, $P<0.001$ ). We conclude that the initial distribution volume of glucose is an indication of cardiac output in normo- and hypovolaemic dogs. Modification of glucose kinetics by the insulin response to glycaemic stimuli was negligible in that short period of time.

Cette étude a pour objet lévaluation, après l'administration de glucose, du rôle de linsuline dans la cinétique du glucose en utilisant un index insulinogène précisant l'ordre de grandeur de la réponse insulinique. Le volume initial de distribution de glucose (VID-G) est calculé grâçe à un modèle à compartiment unique obtenu par des mesures répétées de la glycémie de trois à sept minutes après l'administration de $100 \mathrm{mg} \cdot \mathrm{kg}^{-1}$

\section{Key words}

MEASUREMENT TECHNIQUES: cardiac output; METABOLISM: glucose, insulin.

From the Department of Anesthesiology, University of Hirosaki School of Medicine, Hirosaki-Shi, Aomori-Ken, 036 Japan.

Address correspondence to: Dr. Akitomo Matsuki, University of Hirosaki School of Medicine, Hirosaki-Shi, Aomori-Ken, 036 Japan.

Accepted for publication 28th October, 1993. de glucose. Le VID-G est comparé à la réponse insulinique et au débit cardiaque par thermodilution, mesurés simultanément avant et après une hémorragie provoquée $\left(30 \mathrm{ml} \cdot \mathrm{kg}^{-1}\right.$ en 30 minutes) chez 12 chiens bâtards adultes. La concentration plasmatique de linsuline est mesurée pendant le prélèvement et l'index insulinique calculé. Il n'existe pas de corrélation entre le VID-G et lindex insulinique, mais il en existe une entre le VID- $G$ et le débit cardiaque avant et après l'hémorragie ( $r$ $=0,85, n=24, P<0,001)$. Nous concluons que le volume initial de distribution du glucose correspond au débit cardiaque chez le chien normo- et hypovolémique. Les modifications de la cinétique du glucose par la réponse insulinique au stimulus du glucose sont négligeables pendant cette courte période de temps.

Since the introduction of the Swan-Ganz catheter in 1970 in clinical practice, ${ }^{1}$ the thermodilution technique has become the standard measurement of cardiac output. However, this invasive monitoring procedure has potential hazards and complications. ${ }^{24}$ Other methods of cardiovascular monitoring, which are safer, easier, and less invasive than thermodilution assessments of cardiac output need to be established.

In a previous study, ${ }^{5}$ we calculated the initial distribution volume of glucose (IDV-G) after a bolus of glucose $5 \mathrm{~g}$, using a one-compartment model, in 13 critically ill patients. This value was compared with the thermodilution assessments of cardiac output measured simultaneously. Correlations were found between the IDV-G and the thermodilution cardiac output ( $r=0.89, n=$ 27, $P<0.001$ ). The results indicated that the IDV$G$ reflected cardiac output rather than glucose metabolism. Glucose can be given repeatedly and safely in small amounts unless neurological dysfunction or hyperglycaemia is present. However, the effect of exogenous glucose loading on insulin release remains unresolved, because plasma insulin concentrations were not measured.

The present study was designed to evaluate the role of insulin on glucose kinetics after glucose administration, using the insulinogenic index ${ }^{6}$ as an indicator of the insulin response to an exogenous glucose load. Also, the relationship was determined between the initial distribu- 
tion volume of glucose and thermodilution assessments of cardiac output before and after induced haemorrhage in dogs.

\section{Methods}

The protocol was approved by the animal investigation committee of the institution. Twelve adult mongrel dogs weighing 7-9 kg were used for the experiments. During pentobarbital anaesthesia $\left(30 \mathrm{mg} \cdot \mathrm{kg}^{-1} i v\right)$, the trachea was intubated and the end-tidal carbon dioxide was maintained at $4.5-5.5 \%$ by mechanical ventilation with room air throughout the procedure. The left femoral artery was cannulated for blood sampling and continuous blood pressure monitoring. A Swan-Ganz catheter (Baxter Healthcare Corp. Model 93A-741H-7.5F) was inserted through the right femoral vein and advanced until the tip lay in the pulmonary artery. An infusion of lactated Ringer's solution was begun and continued at a constant rate of $4 \mathrm{ml} \cdot \mathrm{kg}^{-1} \cdot \mathrm{hr}^{-1}$. A period of $30 \mathrm{~min}$ was then allowed to establish a steady circulatory state.

Prior to the glucose administration, cardiac output was measured by cardiac output computer $9520 \mathrm{~A}$ (American Edwards Laboratories) with $5 \mathrm{ml}$ of chilled, normal saline solution. The measurements were performed in duplicate and averaged. The coefficients of variation for repeated measurements were $<5 \%$.

Then $0.5 \mathrm{ml} \cdot \mathrm{kg}^{-1}$ glucose $\left(100 \mathrm{mg} \cdot \mathrm{ml}^{-1}\right)$ was administered through the proximal port of the Swan-Ganz catheter over 30 secs. Blood samples were drawn immediately before and at three, five, seven, and nine minutes after the injection, respectively. Two hours later, haemorrhage was induced by stepwise bleeding (1 $\mathrm{ml} \cdot \mathrm{kg}^{-1} \cdot \mathrm{min}^{-1}$ ) over $30 \mathrm{~min}$. Thirty minutes after completion of the haemorrhage, a second series of measurements and blood sampling was performed. All plasma samples were separated immediately and stored at $-20^{\circ} \mathrm{C}$ until the measurement of glucose and insulin concentrations was completed.

Plasma glucose concentrations were measured using the glucose oxidase method (Gluco-20 glucose analyzer, Fuji Co. Ltd.), and plasma insulin concentrations were measured by radiommunoassay method (ARC-300, ALOKA). Each value was measured in duplicate and averaged.

The initial distribution volume of glucose was calculated, using a one-compartment model, from the incremental plasma glucose decay curve between three and seven minutes after glucose administration. In a one compartment model, the volume of distribution (Vd) is calculated as follows:

$\mathrm{Vd}=$ Dose $/ \mathrm{C}_{0}$

where Dose $=$ amount of drug administered. $C_{0}=$ initial plasma concentration at time zero after instantaneous distribution, but before the start of elimination. The GaussNewton method was used in a microcomputer-based nonlinear least-square programme on the NEC PC-9800 computer ${ }^{7}$. A weight factor of $1 / c^{2}$ was used, where $c$ was the value of the point on the time course. ${ }^{8}$

The insulinogenic index, as described by Seltzer et al., ${ }^{6}$ was calculated by dividing the area circumscribed by the plasma insulin-time curve (i.e., the incremental area above the level before a glucose administration) by the corresponding area circumscribed by the plasma glucose-time curve throughout the nine-minute sampling period.

Numerical data were expressed as mean \pm SD. Statistical analysis was performed using Student's t-test and regression analysis. Values were considered statistically signficant when $P<0.05$.

\section{Results}

The IDV-G, insulinogenic index and cardiac output of each dog are shown in the Table. Mean IDV-G was 1.01 $\pm 0.13 \mathrm{~L}$ before haemorrhage, which decreased to 0.73 $\pm 0.13 \mathrm{~L}$ after haemorrhage. The mean insulinogenic index was reduced from $0.70 \pm 0.49$ to $0.39 \pm 0.43$, and the mean cardiac output from $1.58 \pm 0.52 \mathrm{~L} \cdot \mathrm{min}^{-1}$ before haemorrhage and to $0.63 \pm 0.19 \mathrm{~L} \cdot \mathrm{min}^{-1}$ after haemorrhage.

There was no correlation between the IDV-G and the insulinogenic index $(r=0.19, n=24)$, and the IDV$\mathrm{G}$ and the plasma glucose level immediately before the glucose challenge ( $\mathrm{r}=0.21, n=24)$. A correlation was found between the IDV-G and cardiac output $(\mathrm{r}=0.85$, $n=24, P<0.001$, Figure). Correlations were also found between the IDV-G and cardiac output before $(r=0.63$, $n=12, P<0.05)$ and after bleeding $(\mathrm{r}=0.86, n=$ $12, P<0.001)$.

\section{Discussion}

The present study demonstrated that (1) there was no correlation between the IDV-G and the insulinogenic index, and that (2) a correlation was obtained between the IDV-G and cardiac output. Although glucose disposal takes place in pools more or less distal to plasma, ${ }^{9}$ insulin release may modify glucose kinetics even shortly after glucose administration. In normal subjects, exogenous glucose loading inhibits hepatic glucose output and facilitates insulin release from the pancreas. However, this does not occur in stressed conditions such as sepsis, burns, and surgery ${ }^{10-12}$ as well as in the post-haemorrhagic state of the present study. Although the mean posthaemorrhagic insulinogenic indices in the present study were decreased compared with those before haemorrhage, three of 12 dogs did not show a decrease of the indices as shown in the Table. While each dog showed a con- 
TABLE IDV-G, insulinogenic index and cardiac output before and after haemorrhage

\begin{tabular}{|c|c|c|c|c|c|c|c|}
\hline \multirow[b]{2}{*}{ No } & \multirow{2}{*}{$\begin{array}{l}B W \\
(k g)\end{array}$} & \multicolumn{2}{|l|}{$I D V-G(L)$} & \multicolumn{2}{|c|}{ Insulogenic index } & \multicolumn{2}{|c|}{ Cardiac output $\left(L \cdot \mathrm{min}^{-1}\right)$} \\
\hline & & $B$ & $A$ & $B$ & $A$ & $B$ & $A$ \\
\hline 1 & 8.0 & $0.8 \mathrm{I}$ & 0.68 & 1.46 & 0.61 & 0.82 & 0.40 \\
\hline 2 & 8.0 & 1.18 & 0.92 & 0.04 & 0.04 & 2.57 & 0.87 \\
\hline 3 & 8.0 & 1.11 & 0.75 & 1.20 & 1.50 & 1.54 & 0.81 \\
\hline 4 & 8.5 & 1.04 & 0.77 & 0.36 & 0.06 & 1.03 & 0.70 \\
\hline 5 & 7.0 & 0.87 & 0.61 & 0.39 & 0.11 & 1.54 & 0.46 \\
\hline 6 & 8.0 & 1.09 & 0.88 & 1.09 & 0.77 & 1.51 & 0.93 \\
\hline 7 & 7.5 & 1.12 & 0.77 & 0.53 & 0.71 & 1.69 & 0.60 \\
\hline 8 & 7.0 & 0.99 & 0.84 & 0.63 & 0.29 & 1.73 & 0.66 \\
\hline 9 & 7.0 & 0.89 & 0.59 & 0.66 & 0.04 & 1.68 & 0.54 \\
\hline 10 & 8.0 & 1.16 & 0.80 & 0.27 & 0.18 & 2.13 & 0.62 \\
\hline 11 & 8.5 & 0.95 & 0.72 & 1.49 & 0.24 & 1.97 & 0.68 \\
\hline \multirow[t]{2}{*}{12} & 7.0 & 0.88 & 0.47 & 0.31 & 0.18 & 0.79 & 0.26 \\
\hline & $7.7 \pm 0.6$ & $1.01 \pm 0.13$ & $0.73 \pm 0.13^{*}$ & $0.70 \pm 0.49$ & $0.39 \pm 0.43^{*}$ & $1.58 \pm 0.52$ & $0.63 \pm 0.19^{*}$ \\
\hline
\end{tabular}

B: before haemorrhage; A: after haemorrhage.

Values are mean $\pm \mathrm{SD} ;{ }^{*} P<0.05$ versus $\mathrm{B}$.

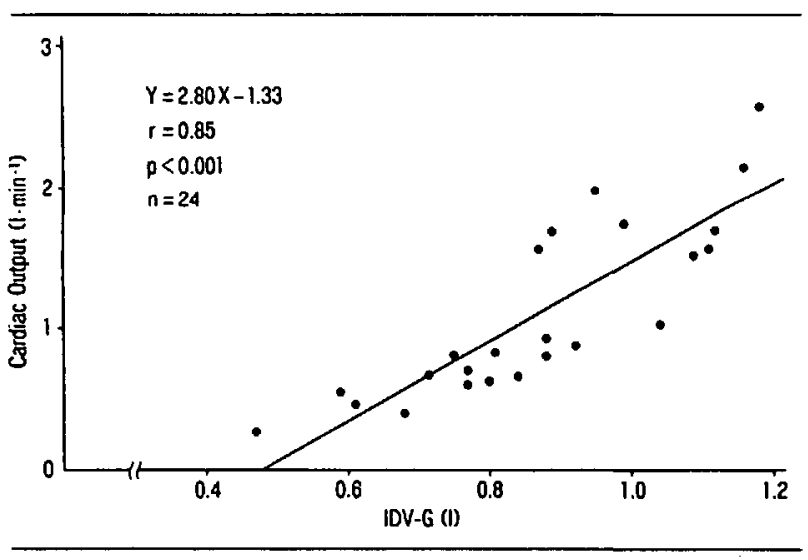

FIGURE Relationship between IDV-G and cardiac output.

sistent decrease in the IDV-G following haemorrhage compared with the pre-haemorrhagic value. Thus, there was no correlation between the insulinogenic index and IDV-G. The insulin response to glycaemic stimuli failed to play an important role for determining the IDV-G. This modifying factor might also be negligible judged from the observation that no consistent relationship was obtained between the IDV-G and the plasma glucose concentration immediately before a glucose challenge.

One may speculate that the initial volume of distribution for several drugs is composed mainly of the blood volume and the extravascular space of the highly perfused tissues such as the heart, lungs, kidney and liver, and is determined by cardiac output, regional blood flow and the characteristics of a particular drug. ${ }^{13}$ The results of the present study suggest that cardiac output is a major determinant of the initial distribution volume of glucose rather than glucose metabolism.

In order to calculate the initial distribution volume in a one-compartment model we had to decide when the distribution phase started and ended, because the longer the interval between drug administration and blood sampling the more would elimination and metabolism modify plasma glucose concentrations. Wolfe et al. ${ }^{14}$ described the rapid decay of plasma concentrations during the first ten minutes after bolus injection which probably represents mixing in the plasma compartment. Cunningham and Heath ${ }^{15}$ have commented that measurements of plasma glucose concentrations at time intervals as short as $1 \mathrm{~min}$ after glucose loading were influenced by slight variation in times of injection and sampling. Thus, a onecompartment model was applied to fit the glucose concentrations versus time data from three to seven minutes after the injection, and the data obtained after nine minutes were disregarded.

Induced haemorrhage produces a decrease in circulating blood volume and cardiac output. It appears that the IDV-G reflects blood volume in the body, because cardiac output correlates with preload. However, this is not always true especially in patients with congestive heart failure where contractility and/or afterload may also be important determinants of cardiac output as well as the preload. Thus, the IDV-G method, when used to predict cardiac output, should apply only to patients without compromised cardiac contractility.

\section{Conclusion}

The insulin response to a glucose load did not correlate with the IDV-G. The contribution of insulin to the change 
of plasma glucose concentration was negligible in a short time after glucose loading. The IDV-G correlated with thermodilution assessments of cardiac output under the experimental conditions described.

\section{Acknowledgements}

The authors wish to thank Emeritus Professor J.W.R. McIntyre (Edmonton, Canada) and Professor A.H. Giesecke (Dallas, USA) for their valuable comments, and Miss M. Kudoh for her secretarial help.

\section{References}

1 Swan HJC, Ganz W, Forrester JS, Marcus H, Diamond $G$, Chonette $D$. Catheterization of the heart in man with use of flow-directed balloon-tipped catheter. $\mathbf{N}$ Engl $\mathbf{J}$ Med 1970; 283: 447-51.

2 Pace NL. A critique of flow-directed pulmonary arterial catheterization. Anesthesiology 1977; 47: 455-65.

3 Sise MJ, Hollingsworth P, Brimm JE, Peters RM, Virgilio $R W$, Shackford $S R$. Complications of the flow-directed pulmonary-artery catheter: a prospective analysis in 219 patients. Crit Care Med 1981; 9: 315-8.

4 Robin ED. Death by pulmonary artery flow-directed catheter: time for a moratorium? (Editorial). Chest 1987; 92: $727-31$.

5 Ishihara $H$, Shimodate $Y$, Koh H, Isozaki $K$, Tsubo T, Matsuki $A$. The initial distribution volume of glucose and cardiac output in the critically ill. Can J Anaesth 1993; 40: 28-31.

6 Seltzer HS, Allen EW, Herron AL Jr., Brennan MT. Insulin secretion in response to glycemic stimulus: relation of delayed initial release to carbohydrate intolerance in mild diabetes mellitus. J Clin Invest 1967; 46: 323-35.

7 Yamaoka K, Tanigawara Y, Nakagawa T, Uno T. A pharmacokinetic analysis program (MULTI) for microcomputer. J Pharmacodyn 1981; 4: 879-85.

8 Yamaoka $K$, Nakagawa T, Tanaka H, Yasuhara $M$, Okumura $K$, Hori $R$. A nonlinear multiple regression program, MULT12 (Bayes), based on bayesian algorithm for microcomputers. J Pharmacodyn 1985; 8: 246-56.

9 Cobelli C, Bier DM, Ferranini E. Modeling glucose metabolism in man: theory and practice. Horm Metab Res (Suppl) 1990; 24:1-10.

10 Moorhouse JA, Steinberg J, Tessler BB. Effect of glucose dose upon intravenous glucose tolerance in health and in diabetes. J Clin Endocrinol Metab 1963; 23: 1074-9.

11 Wilmore DW, Mason AD Jr., Pruitt BA Jr. Impaired glucose flow in burned patients with gram-negative sepsis. Surg Gynecol Obstet 1976; 143: 720-4.

12 Giddings AEB, Mangnall D, Rowlands BJ, Clark RG. Plasma insulin and surgery I. Early changes due to operation in the insulin response to glucose. Ann Surg 1977; 186: 681-6.
13 Ghoneim M, Pearson K. Pharmacokinetics of drugs administered intravenously. In: Scurr C, Feldman S, Soni $\mathrm{N}$ (Eds.). Scientific Foundations of Anaesthesia, 4th ed., Chicago: Year Book Medical Publishers, 1990; 559-71.

14 Wolfe RR, Allsop JR, Burke JF. Fallibility of the intravenous glucose tolerance test as a measure of endogenous glucose turnover. Metabolism 1978; 27: 217-26.

15 Cunningham VJ, Heath DF. An interpretation of the intravenous glucose tolerance test in the light of recent findings on the kinetics of glucose and insulin in man. Clin Sci 1978; 54: 161-73. 